\title{
An unusual cause of an acute abdomen (2009: 10a)
}

(C) European Society of Radiology 2009

\section{Case report}

A 49-year-old woman presented to the Accident and Emergency Department with a 6-day history of central abdominal pain made worse by eating. She had not moved her bowels during this period but was passing small amounts of flatus. She had lost her appetite but had not lost weight significantly.

She had no significant past surgical, medical or family history, and was not taking any prescription medications.

On examination, her blood pressure was $145 / 95 \mathrm{mmHg}$ and her pulse rate was 96 beats $/ \mathrm{min}$. Abdominal examination revealed generalised abdominal tenderness, maximal in the epigastrium, and the suggestion of an epigastric mass. On auscultation, there were active bowel sounds. No abnormality was detected on rectal examination.

Blood tests revealed a white-blood-cell count of $21.6 \times$ $10^{9} / \mathrm{L}$ (normal range $4-11 \times 10^{9}$ ) and a C-reactive protein of $295 \mathrm{mg} / \mathrm{L}$ (normal range $0-5$ ).

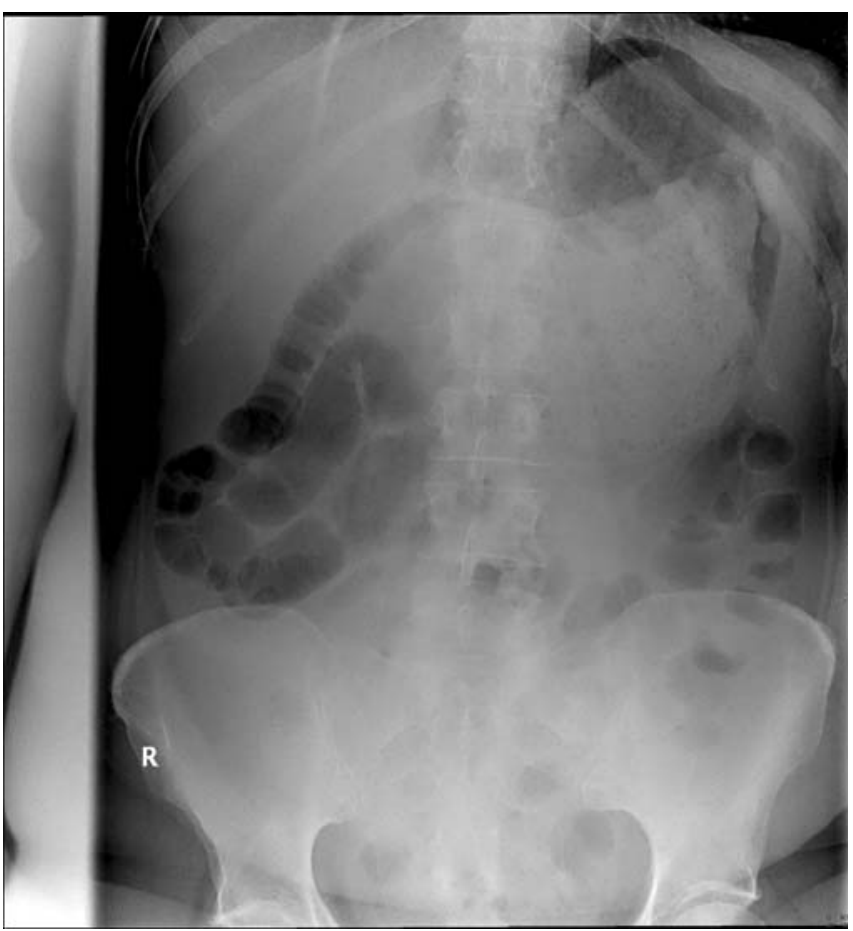

Fig. 1 Supine abdominal radiograph
A supine abdominal radiograph (Fig. 1) and a CT study of the abdomen (Fig. 2) were performed.

\section{What is the diagnosis?}

Readers are invited to supply one possible diagnosis via electronic means to: robert.hermans@uzleuven.be

The subject of the email should include 'Interpretation Corner' and the number given above (Interpretation Corner 2009:10a).

They should include their name, title, address, FAX and phone number.

Deadline: one clear calendar month from distribution date.

The names of the first 25 radiologists submitting the correct diagnosis will be published (only one from any individual centre and none from the host institution!).

Three months after the initial publication of the case history, the authors will publish the final diagnosis.

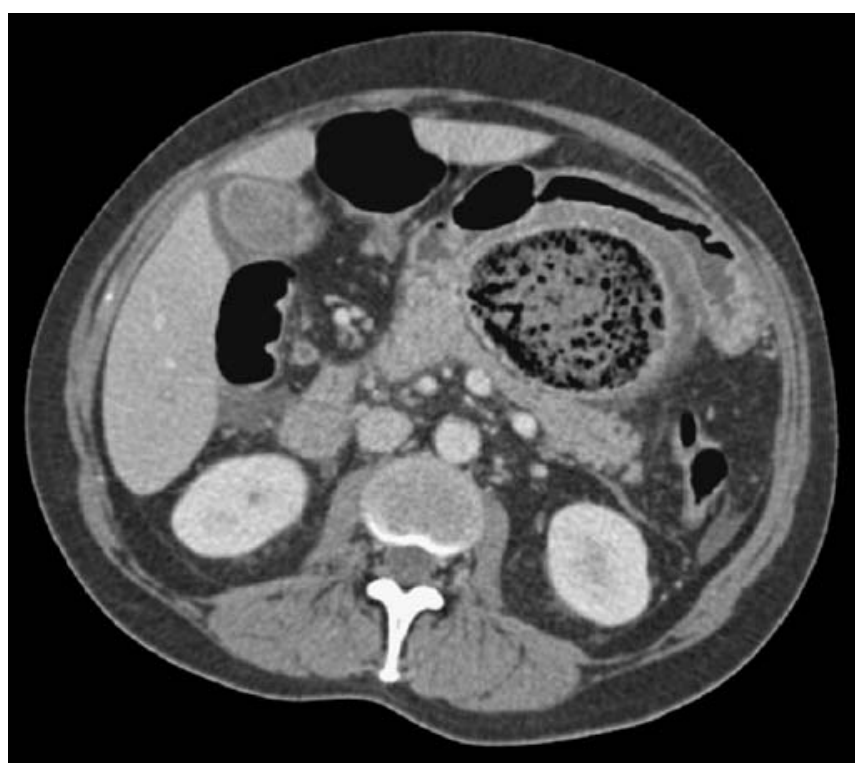

Fig. 2 Axial contrast-enhanced CT image 